\title{
Calculation of Contact Angles at Triple Phase Boundary in Solid Oxide Fuel Cell Anode Using the Level Set Method
}

\author{
Xiaojun Sun ${ }^{\mathrm{a}}$, Yosuke Hasegawa ${ }^{\mathrm{a}, \mathrm{b}}$, Haruhiko Kohno ${ }^{\mathrm{c}}$, Zhenjun Jiao ${ }^{\mathrm{a}, \mathrm{b}}$, Koji Hayakawa ${ }^{\mathrm{a}}$, \\ Kohei Okita $^{\mathrm{d}}$ and Naoki Shikazono ${ }^{\mathrm{a}, \mathrm{b}^{*}}$ \\ ${ }^{a}$ Institute of Industrial Science, The University of Tokyo \\ ${ }^{\mathrm{b}}$ CREST, JST \\ ${ }^{\mathrm{c}}$ Department of Mechanical Information Science and Technology, Kyushu Institute of Technology \\ ${ }^{\mathrm{d}}$ College of Industrial Technology, Nihon University \\ *Corresponding author. Tel\&Fax.: +81-354526776 \\ E-mail address: shika@iis.u-tokyo.ac.jp
}




\section{Abstract:}

A level set method is applied to characterize the three dimensional structures of nickel, yttria stabilized zirconia and pore phases in solid oxide fuel cell anode reconstructed by focused ion beam-scanning electron microscope. A numerical algorithm is developed to evaluate the contact angles at the triple phase boundary based on interfacial normal vectors which can be calculated from the signed distance functions defined for each of the three phases. Furthermore, surface tension force is estimated from the contact angles by assuming the interfacial force balance at the triple phase boundary. The average contact angle values of nickel, yttria stabilized zirconia and pore are found to be $143^{\circ} \sim 156^{\circ}, 83^{\circ} \sim 138^{\circ}$ and $82^{\circ} \sim 123^{\circ}$, respectively. The mean contact angles remained nearly unchanged after 100 hours operation. However, the contact angles just after reduction are different for the cells with different sintering temperatures. In addition, standard deviations of the contact angles are very large especially for yttria stabilized zirconia and pore phases. The calculated surface tension forces from mean contact angles were close to the experimental values found in the literature. Slight increase of surface tensions of nickel/pore and nickel/yttria stabilized zirconia were observed after operation. Present data are expected to be used not only for the understanding of the degradation mechanism, but also for the quantitative prediction of the microstructural temporal evolution of solid oxide fuel cell anode.

Key words: Solid oxide fuel cell anode, Microstructure, Contact angle, Surface tension, Level set method, Focused ion beam scanning electron microscopy 


\section{Introduction}

Solid oxide fuel cell (SOFC) is one of the most efficient devices for converting hydrocarbon fuels into electrical power and possesses high fuel flexibility [1]. Thus, it is expected as a promising power generation device in the near future. SOFC is usually operated in the temperature range of 973 to $1273 \mathrm{~K}$, which results in the challenges of long time stability and durability. Performance degradation of electrodes has been considered to be one of the major obstacles for commercialization. It is widely accepted that the electrochemical reactions in the nickel(Ni)- yttria stabilized zirconia(YSZ)anode take places at confined spatial sites called triple phase boundary (TPB) where YSZ, nickel and pore are in contact. Therefore, the three dimensional microstructures of the anode have a significant impact on the resultant performance of SOFC [2]. Thus, quantifying the morphology of triple phase boundary is very important for understanding the anode degradation. A number of studies on anode microstructure have been carried out in order to characterize and quantify the cell performance and degradation process. Microstructural parameters such as surface area, volume fraction, triple phase boundary length and tortuosity factor are calculated to evaluate the anode performance $[3,4]$. Comparison with the impedance spectroscopy data is useful to determine the relationship between polarization resistance and microstructural change [5]. Chen et al. [6] simulated the coarsening process of Ni-YSZ composite anode by the phase field method in order to predict temporal evolution of cell performance. The coarsening kinetics of Ni-YSZ anodes has 
been found to be strongly related to the Ni-YSZ contact angles [6].In their simulation results, two contact angles are assumed to be fixed, that is, $93^{\circ}$ and $120^{\circ}$. However, these values are taken from experimental or empirical values. Tsoga et al. [7] experimentally measured the non-reactive contact angle between $\mathrm{Ni}$ and $8 \mathrm{YSZ}$ at $1500^{\circ} \mathrm{C}$ and reported that the contact angle is $117^{\circ}$. The contact angle and surface tension force are indispensable parameters for the simulations of Ni-YSZ anode coarsening process such as a phase field method [6] and a Monte Carlo method [8].However, studies on contact angles and surface tension forces of Ni-YSZ anode are still very limited. In the present study, we develop a numerical method to calculate the contact angles and surface tension forces of the Ni-YSZ anode using the Ni-YSZ anode microstructure reconstructed by focused ion beam-scanning electron microscope (FIB-SEM) [4].

\section{Experiment}

Electrolyte-supported button cell is used in this study. The anode cermet was prepared by ball-milling NiO and YSZ powders (AGC Seimi Chem. Corp.) for 48 hours where the volume ratio of Ni to YSZ is 43:57. The powder was then mixed with terpineol solvent and the ethylcellulose binder in an agate mortar to obtain anode slurry. The slurry was screen-printed onto commercial dense $8 \mathrm{~mol} \%$ YSZ pellet (diameter $20 \mathrm{~mm}$, thickness $0.5 \mathrm{~mm}$, Fine Ceramics Corp., Japan) with a diameter of $10 \mathrm{~mm}$, and then sintered in an electric furnace [3]. The anodes were discharged in $3 \%$ $\mathrm{H}_{2} \mathrm{O}$ humidified hydrogen with a current density of $0.2 \mathrm{Acm}^{-2}$ at $800{ }^{\circ} \mathrm{C}$. In order to investigate the 
effects of sintering temperature on contact angles and surface tension, the anodes were sintered at three different temperatures, $1400{ }^{\circ} \mathrm{C}, 1450^{\circ} \mathrm{C}$, and $1500^{\circ} \mathrm{C}$. The anode sample after experiments were observed by FIM-SEM (Carl Zeiss, NVision 40) [3]. The samples were first infiltrated by epoxy resin under low pressure atmosphere (ca. 15Pa), so that the pores of the porous electrode could be easily distinguished during FIB-SEM observation. The cured samples were then polished by Ar-ion beam cross-section polisher (JEOL Ltd., SM-09010). The details of dual-beam FIB-SEM observation procedure has been introduced in [4]. The 3D microstructure of the Ni-YSZ anode as shown in Fig.1 was then virtually reconstructed based on a series of 2D images by Matlab and Avizo Fire 6.0 (Maxnet). It was reported that the anode sintered at $1450^{\circ} \mathrm{C}$ provided best initial performance and the lowest degradation rate compared to the anode sintered at other temperatures [9]. Table 1 shows the sizes of anode samples sintered at $1400{ }^{\circ} \mathrm{C}, 1450^{\circ} \mathrm{C}$, and $1500^{\circ} \mathrm{C}$.

\section{Numerical Method}

\subsection{Level set method}

The level set method developed by Osher\&Sethian $[10,11,12]$ is a numerical technique for tracking deformed interfaces. One of the advantages of the level set method is that one can handle moving interfaces or surfaces on a fixed Cartesian grid without explicitly tracking the interface. In the level 
set method, the interface $\Gamma$ is represented implicitly as the zero level set surface of a continuous function $\phi$. Therefore, it can be expressed as

$$
\Gamma=\{x \mid \phi(x, t)=0\}
$$

The interfacial normal vector $\vec{n}$ is defined at the interface by the following equation:

$$
\vec{n}=\frac{\nabla \phi}{|\nabla \phi|}
$$

Fig. 2 shows the process of obtaining level set function from FIB-SEM reconstructed data. A series of two dimensional (2D)cross-section images of each sample are obtained by FIB-SEM measurement. Since cubic voxel is desirable in the calculation, the 2D images are resized to a cubic structure. The resized images are reconstructed into three dimension by Avizo software(FEI Visualization Sciences Group) as shown in Fig. 3. Then,SDF-lib C++ library code [13] is used to obtain signed distance functions of Ni, YSZ and pore from the output files of Avizo.

The level set function and the original FIB-SEM structures are compared in Fig.4. A 2D image from FIB-SEM is shown in Fig.4(a), whose pixel sizeis33.9× $33.9 \times 33.9 \mathrm{~nm}^{3}$. Calculated level set functions of Ni, YSZ and pore phases are visualized in Fig.4 (b), (c), and (d),respectively. As a whole, good agreement is obtained between the original SEM image and the calculated level set functions, although some trivial differences can be seen. It was found that level set structure largely depends on the resolution of the microstructure, which means that highest resolution in FIB-SEM is favorable for accurate shape prediction using the level set function. 


\subsection{Calculation of normal vectors and contact angles at the TPB}

A schematic of TPB is shown in Fig.5. Ni, YSZ and pore are represented by the three different level

set functions, $\phi_{\mathrm{Ni}}, \phi_{\mathrm{YSZ}}$ and $\phi_{\mathrm{Pore}}$, respectively. Using Eq. (2), the normal vector of the interface between $\mathrm{Ni}$ and pore is given as follows:

$$
\vec{n}_{\mathrm{Ni} / \text { Pore }}=\frac{\nabla \phi_{\mathrm{Ni}}}{\left|\nabla \phi_{\mathrm{Ni}}\right|} \text { at.Ni-pore interface. }
$$

Similarly, the normal vectors of the other interfaces are expressed as

$$
\begin{aligned}
\vec{n}_{\mathrm{Ni} / \mathrm{YSZ}} & =\frac{\nabla \phi_{\mathrm{Ni}}}{\left|\nabla \phi_{\mathrm{Ni}}\right|} \text { at Ni-YSZ interface, } \\
\vec{n}_{\mathrm{YSZ} / \mathrm{Ni}} & =\frac{\nabla \phi_{\mathrm{YSZ}}}{\left|\nabla \phi_{\mathrm{YSZ}}\right|} \text { at YSZ-Ni interface, } \\
\vec{n}_{\mathrm{YSZ} / \mathrm{Pore}} & =\frac{\nabla \phi_{\mathrm{YSZ}}}{\left|\nabla \phi_{\mathrm{YSZ}}\right|} \text { at YSZ-pore interface, } \\
\vec{n}_{\text {Pore/Ni }} & =\frac{\nabla \phi_{\text {Pore }}}{\left|\nabla \phi_{\text {Pore }}\right|} \text { at pore- Ni interface, } \\
\vec{n}_{\text {Pore/YSZ }} & =\frac{\nabla \phi_{\text {Pore }}}{\left|\nabla \phi_{\text {Pore }}\right|} \text { at pore-YSZ interface, }
\end{aligned}
$$

where subscript $\mathrm{A} / \mathrm{B}$ indicates the interface between $\mathrm{A}$ and $\mathrm{B}$ phases.

According to the geometrical relationship shown in Fig.1, the contact angles of Ni, YSZ and

pore are calculated as follows:

$$
\begin{aligned}
& \theta_{\mathrm{Ni}}=180^{\circ}-\arccos \left(\vec{n}_{\mathrm{Ni} / \mathrm{Pore}} \cdot \vec{n}_{\mathrm{Ni} / \mathrm{YSZ}}\right), \\
& \theta_{\mathrm{YSZ}}=180^{\circ}-\arccos \left(\vec{n}_{\mathrm{YSZ} / \mathrm{Ni}} \cdot \vec{n}_{\mathrm{YSZ} / \mathrm{Pore}}\right), \\
& \theta_{\text {Pore }}=180^{\circ}-\arccos \left(\vec{n}_{\mathrm{Pore} / \mathrm{Ni}} \cdot \vec{n}_{\mathrm{Pore} / \mathrm{YSZ}}\right) .
\end{aligned}
$$

At the TPB, ideally, the six normal vectors given by Eqs. (3) to (8) should lie on the same 
two-dimensional plane, which is orthogonal to the direction of the TPB. However, due to the limited resolution of the digitized FIB-SEM data, numerical errors are unavoidable during the successive procedures. In addition it is not always ensured that all the six vectors exist on the same plane. Consequently, the sum of $\theta_{\mathrm{Ni}}, \theta_{\mathrm{YSZ}}$ and $\theta_{\text {Pore }}$ cannot amount to be exactly $2 \pi$.In order to overcome the difficulty mentioned above, the six normal vectors in Eqs. (3) to (8) are projected on the single plane which is orthogonal to the most likely direction of the TPB.

As shown in Fig. 5, the normal vectors of Ni, YSZ and Pore at TPB are given respectively according to Eq. (2) as follows:

$$
\vec{n}_{\mathrm{Ni}}=\frac{\nabla \phi_{\mathrm{Ni}}}{\left|\nabla \phi_{\mathrm{Ni}}\right|}, \quad \vec{n}_{\mathrm{YSZ}}=\frac{\nabla \phi_{\mathrm{YSZ}}}{\left|\nabla \phi_{\mathrm{YSZ}}\right|}, \quad \vec{n}_{\text {Pore }}=\frac{\nabla \phi_{\text {Pore }}}{\left|\nabla \phi_{\text {Pore }}\right|} .
$$

Then we try to calculate the most-likely TPB direction unit vector $\vec{a}$ which is normal to all the three normal vectors in Eq. (12) by applying a least square method. For simplicity, the three normal vectors in Eq. (12) are denoted as $\overrightarrow{b_{j}^{1}}, \overrightarrow{b_{j}^{2}}$ and $\overrightarrow{b_{j}^{3}}$, respectively. The subscript $j$ represents the vector component in $x, y, z$ directions and superscripts $1,2,3$ represent Ni, YSZ and Pore. The most-likely TPB direction is defined so as to minimize $J$, which is the sum of the square of the inner products between the TPB direction and the normal vectors.

$$
J=\sum_{k=1}^{3}\left(a_{1} b_{1}^{k}+a_{2} b_{2}^{k}+a_{3} b_{3}^{k}\right)^{2}
$$

Since $\vec{a}$ is a unit vector from its definition, $\vec{a}$ needs to satisfy the following condition: 


$$
a_{1}^{2}+a_{2}^{2}+a_{3}^{2}=1
$$

The above problem can be considered as a minimization problem of $J$ under the restriction given by

Eq. (14). This is equivalent to solve the minimizing problem of Lagrangian $L$ defined as follows:

$$
L=\sum_{k=1}^{3}\left(a_{1} b_{1}^{k}+a_{2} b_{2}^{k}+a_{3} b_{3}^{k}\right)^{2}-\lambda\left(a_{1}^{2}+a_{2}^{2}+a_{3}^{2}-1\right)
$$

where $\lambda$ is a Lagrangian multiplier.

The differentials of $L$ with respect to the vector component of $\vec{a}$ are given as follows:

$$
\begin{aligned}
& \frac{\partial L}{\partial a_{1}}=2\left\{\left(B_{11}-\lambda\right) a_{1}+B_{12} a_{2}+B_{13} a_{3}\right\}, \\
& \frac{\partial L}{\partial a_{2}}=2\left\{B_{12} a_{1}+\left(B_{22}-\lambda\right) a_{2}+B_{23} a_{3}\right\}, \\
& \frac{\partial L}{\partial a_{3}}=2\left\{B_{13} a_{1}+B_{23} a_{2}+\left(B_{33}-\lambda\right) a_{3}\right\},
\end{aligned}
$$

where

$$
B_{i j}=\sum_{k=1}^{3} b_{i}^{k} b_{j}^{k} .
$$

The most likely TPB direction vector $\vec{a}$ is obtained by simultaneously satisfying the stationary conditions, i.e., $\frac{\partial L}{\partial a_{1}}=\frac{\partial L}{\partial a_{2}}=\frac{\partial L}{\partial a_{3}}=0$, and Eq. (14). Since it turns out to be impossible to obtain $\vec{a}$ analytically, we employ the following iterative procedure. Suppose a candidate of $\vec{a}$ is given by the cross product of normal vector of Ni and YSZ in Eq. (12)as follows:

$$
\vec{a}=\vec{n}_{N i} \times \vec{n}_{Y S Z}
$$

We attempt to correct $\vec{a}$ so as to converge it to the solution minimizing $J$. In accordance with Eqs. (16) to (18), the correction $\Delta a_{j}$ of each vector component should be given as follows: 


$$
\begin{aligned}
& \Delta a_{1}=-\frac{\partial L}{\partial a_{1}}=-2\left\{\left(B_{11}-\lambda\right) a_{1}+B_{12} a_{2}+B_{13} a_{3}\right\}, \\
& \Delta a_{2}=-\frac{\partial L}{\partial a_{2}}=-2\left\{B_{12} a_{1}+\left(B_{22}-\lambda\right) a_{2}+B_{23} a_{3}\right\}, \\
& \Delta a_{3}=-\frac{\partial L}{\partial a_{3}}=-2\left\{B_{13} a_{1}+B_{23} a_{2}+\left(B_{33}-\lambda\right) a_{3}\right\} .
\end{aligned}
$$

Considering that the vector norm is kept unity after the correction,

$$
a_{1}^{2}+a_{2}^{2}+a_{3}^{2}=\left(a_{1}+\Delta a_{1}\right)^{2}+\left(a_{2}+\Delta a_{2}\right)^{2}+\left(a_{3}+\Delta a_{3}\right)^{2}=1 \text {. }
$$

Therefore, we obtain

$$
a_{1} \Delta a_{1}+a_{2} \Delta a_{2}+a_{3} \Delta a_{3}=0
$$

Here, the products of the correction such as $\Delta a_{i} \Delta a_{j}$ are neglected, since they are sufficiently smaller than the first order of $\Delta a_{j}$.

The Lagrangian multiplier $\lambda$ in Eqs. (21) to (23) can be determined so as to satisfy Eq. (25), which results in:

$$
\lambda=B_{11} a_{1}^{2}+B_{22} a_{2}^{2}+B_{33} a_{3}^{2}+2\left(B_{12} a_{1} a_{2}+B_{23} a_{2} a_{3}+B_{13} a_{1} a_{3}\right) .
$$

Finally, the present iterative procedure is summarized as follows.

1) Determine a candidate of $\vec{a}$ by Eq. (20).

2) Calculate $\lambda$ by solving Eq. (26).

3) Calculate the corrections of each vector component by Eqs. (21) to (23).

4) Update $\vec{a}$ by adding $\Delta a_{j}$, i.e. $a_{j}+\Delta a_{j}$.

5) Iterate the above procedures until the resultant $\vec{a}$ converges.

\subsection{Calculation of contact angles}

In this sub-section, six normal vectors given by Eqs. (3) to (8)are projected onto the plane which is 
normal to most likely TPB vector $\vec{a}$. Fig. 6shows the case where $\vec{n}_{\text {YSZ/Pore }}$ does not lie on the plane orthogonal to $\vec{a}$. The cross product of normal vectors $\vec{a}$ and $\vec{n}_{\text {YsZ/Pore are used to obtain the }}$ following projected normal vector:

$$
\tilde{n}_{\text {YSZ/Pore }}=\frac{\vec{a} \times \vec{n}_{\text {YSZ/Pore }} \times \vec{a}}{\left|\vec{a} \times \vec{n}_{\text {YSZ/Pore }} \times \vec{a}\right|} .
$$

The other five normal vectors in Eqs. (3) to (8) are also projected onto this plane in the same way.

They are respectively denoted by $\tilde{n}_{\mathrm{Ni} / \text { Pore }}, \tilde{n}_{\mathrm{Ni} / \mathrm{YSZ}}, \tilde{n}_{\mathrm{YSZ} / \mathrm{Ni}}, \tilde{n}_{\text {Pore } / \mathrm{Ni}}$ and $\tilde{n}_{\text {Pore/YSZ }}$ as shown in Fig. 7.

Ideally, two normal unit vectors of different level set functions at the interface should lie on a single straight line. However, the normal vectors projected onto the most likely TPB direction no longer satisfy this condition exactly as schematically shown in Fig. 7. For example, the projected $\tilde{n}_{\text {Ni/Pore }}$ and $\tilde{n}_{\text {Pore/Ni vectors are not pointing the opposite direction. Hence, we make the final }}$ modification so as to align them in the same direction as shown by the yellow vectors in Fig. 7. The resultant orthogonal vectors of the interfaces are obtained by the difference of two normal vectors on the same numerical grid as follows:

$$
\begin{aligned}
\bar{n}_{\mathrm{YSZ} / \mathrm{Ni}} & =\frac{\tilde{n}_{\mathrm{YSZ} / \mathrm{Ni}}-\tilde{n}_{\mathrm{Ni} / \mathrm{YSZ}}}{\left|\tilde{n}_{\mathrm{YSZ} / \mathrm{Ni}}-\tilde{n}_{\mathrm{Ni} / \mathrm{YSZ}}\right|}, \\
\bar{n}_{\text {Pore/YSZ }} & =\frac{\tilde{n}_{\text {Pore/YSZ }}-\tilde{n}_{\mathrm{YSZ} / \mathrm{Pore}}}{\left|\tilde{n}_{\text {Pore/YSZ }}-\tilde{n}_{\mathrm{YSZ} / \mathrm{Pore}}\right|},
\end{aligned}
$$




$$
\bar{n}_{\text {Ni/Pore }}=\frac{\tilde{n}_{\text {Ni/Pore }}-\tilde{n}_{\text {Pore } / \mathrm{Ni}}}{\left|\tilde{n}_{\text {Ni/Pore }}-\tilde{n}_{\text {Pore } / \mathrm{Ni}}\right|} .
$$

Accordingly, the other three opposite normal vectors are obtained as

$$
\begin{gathered}
\bar{n}_{\mathrm{Ni} / \mathrm{YSZ}}=-\frac{\tilde{n}_{\mathrm{YSZ} / \mathrm{Ni}}-\tilde{n}_{\mathrm{Ni} / \mathrm{YSZ}}}{\left|\tilde{n}_{\mathrm{YSZ} / \mathrm{Ni}}-\tilde{n}_{\mathrm{Ni} / \mathrm{YSZ}}\right|}, \\
\bar{n}_{\mathrm{YSZ} / \mathrm{Pore}}=-\frac{\tilde{n}_{\text {Pore } / \mathrm{YSZ}}-\tilde{n}_{\mathrm{YSZ} / \mathrm{Pore}}}{\left|\tilde{n}_{\text {Pore } / \mathrm{YSZ}}-\tilde{n}_{\mathrm{YSZ} / \text { Pore }}\right|}, \\
\bar{n}_{\text {Pore } / \mathrm{Ni}}=-\frac{\tilde{n}_{\mathrm{Ni} / \mathrm{Pore}}-\tilde{n}_{\text {Pore/Ni }}}{\left|\tilde{n}_{\mathrm{Ni} / \mathrm{Pore}}-\tilde{n}_{\text {Pore } / \mathrm{Ni}}\right|} .
\end{gathered}
$$

Finally, the six normal vectors Eqs. (28) to (33) are applied to calculate the contact angles on the

triple phase boundary. Namely, Eqs. (9)to (11) are modified as follows:

$$
\begin{aligned}
\bar{\theta}_{\mathrm{Ni}} & =180-\arccos \left(\bar{n}_{\mathrm{Ni} / \mathrm{YSZ}} \cdot \bar{n}_{\mathrm{Ni} / \text { Pore }}\right), \\
\bar{\theta}_{\mathrm{YSZ}} & =180-\arccos \left(\bar{n}_{\mathrm{YSZ} / \mathrm{Ni}} \cdot \bar{n}_{\mathrm{YSZ} / \mathrm{Pore}}\right), \\
\bar{\theta}_{\text {Pore }} & =180-\arccos \left(\bar{n}_{\mathrm{Pore} / \mathrm{YSZ}} \cdot \bar{n}_{\text {Pore } / \mathrm{Ni}}\right) .
\end{aligned}
$$

This way, it is guaranteed that the sum of the three angles becomes exactly $2 \pi$, i.e.,

$\bar{\theta}_{\mathrm{Ni}}+\bar{\theta}_{\mathrm{YSZ}}+\bar{\theta}_{\mathrm{Pore}}=2 \pi$

\subsection{Calculation of surface tension forces}

Assuming a static force balance at TPB, the surface tension of interfaces can be calculated from the obtained contact angles. The surface tensions acting at TPB are illustrated in Fig.8. The balance of 
the surface tensions at TPB in equilibrium leads to the following relationships in the two orthogonal directions:

$$
\begin{gathered}
\gamma_{\mathrm{Ni} / \mathrm{YSZ}}+\gamma_{\mathrm{N} i \text { Pore }} \cos \bar{\theta}_{\mathrm{Ni}}+\gamma_{\mathrm{YSZ} / \mathrm{Pore}} \cos \bar{\theta}_{\mathrm{YSZ}}=0 . \\
\gamma_{\mathrm{N} / \text { Pore }} \sin \bar{\theta}_{\mathrm{Ni}}=\gamma_{\mathrm{YSZ} / \mathrm{Pore}} \sin \bar{\theta}_{\mathrm{YSZ}} .
\end{gathered}
$$

\section{Results and Discussions}

The calculated average contact angles of three samples sintered at $1400{ }^{\circ} \mathrm{C}$ are listed in Table2. The total sums of three angles are always $360^{\circ}$, which means that six normal vectors are successfully projected onto the plane orthogonal to TPB. This validates the present calculation process. The average contact angles of $\mathrm{Ni}, \mathrm{YSZ}$ and pore are $143^{\circ} \sim 147^{\circ}, 93^{\circ} \sim 98^{\circ}$ and $119^{\circ} \sim 123^{\circ}$, respectively. Chen et al. [14] used $141^{\circ}, 121^{\circ}$ and $98^{\circ}$ for the equilibrium contact angles of Ni, YSZ and pore in their model, assuming that YSZ phase has a very small mobility. However, FIB-SEM images show that the contact angle of YSZ is around $95^{\circ}$, which is much smaller than the value used in Chen et al.[14]. Probability density functions of contact angles are plotted in Figs. 9 to 11. Although average contact angle of Ni keeps almost unchanged after $100 \mathrm{~h}$ and $250 \mathrm{~h}$ discharge, distribution profiles are quite different from each other. In addition, standard deviations of the contact angles are very large especially for YSZ and pore phases. Table 3 shows standard deviations of average contact angles after $650 \mathrm{~h}$ discharge for the samples sintered at $1450{ }^{\circ} \mathrm{C}$. Average contact angles and standard deviations during $100 \mathrm{~h}$ discharge for the samples sintered at $1500{ }^{\circ} \mathrm{C}$ are shown in Table 4 . From the 
tables, we can see that the contact angles of different sintering temperature samples are quite different, which indicates the complex nature of the sintering process.

If surface tension of any one phase is known, surface tensions of other two interfaces can be calculated assuming a static balance. In the present study, the surface tension value of $1.4 \mathrm{Jm}^{-2}$ for YSZ/Pore which is reported in Ref. [6] is used to calculate the surface tension forces of Ni/Pore and Ni-YSZ. Surface tensions of each interface for the sample sintered at $1400{ }^{\circ} \mathrm{C}$ are given in Table 5 . The surface tension values of approximately1.9 $\mathrm{Jm}^{-2}$ for Ni/Pore and $1.95 \mathrm{Jm}^{-2}$ for Ni-YSZ are reported in Refs. [15] and[6]. These values are close to our calculation results. Tables6and 7 show the surface tension on the interface for the sample sintered at $1450{ }^{\circ} \mathrm{C}$ and $1500{ }^{\circ} \mathrm{C}$, respectively. From Tables 5 to 7 , it can be noted that surface tensions of Ni/Pore and Ni-YSZ seem to show some increase after operation.

\section{Conclusions}

In the present study, a level set method is applied to calculate the contact angles at the triple phase boundary of Ni-YSZ anode reconstructed by FIB-SEM. An accurate estimation method of the contact angles at the triple phase boundary is proposed to overcome the limited resolution of images obtained by FIB-SEM and the resultant numerical errors in the level set function. A proposed numerical technique to estimate the most probable TPB direction from the interfacial normal vectors 
gave exactly $2 \pi$ for the total sum of the three angles. This validates that the present interpolation approach works well. The average contact angle values of Ni, YSZ and pore are found to be $143^{\circ} \sim 156^{\circ}, 83^{\circ} \sim 138^{\circ}$ and $82^{\circ} \sim 123^{\circ}$, respectively. The mean contact angles remained nearly unchanged after operation. However, the contact angles just after reduction showed large difference for the cells with different sintering temperatures. In addition, standard deviations of the contact angles are very large especially for YSZ and pore phases. The calculated surface tension forces from mean contact angles were close to the experimental values found in the literature. Slight increase of surface tensions of $\mathrm{Ni} /$ Pore and $\mathrm{Ni} / \mathrm{YSZ}$ were observed after operation. The obtained average contact angles surface tension data are expected to be used as basic parameters for simulating Ni-YSZ anode coarsening, which is regarded as one of main causes for degradation.

\section{Acknowledgments}

This work was partly supported by Japan Science and Technology Agency (JST) CREST program and the New Energy and Industrial Technology Development Organization (NEDO) SOFC Project.

[1] C. S. Subhash and K. Kendall, High Temperature Solid Oxide Fuel Cells: Fundamentals, Design and Applications, Elsevier Advanced Technology (2003).

[2] R. Hayre, D. M. Barnett, F. Prinz, The Triple Phase Boundary, A Mathematical Model and Experimental Investigations for Fuel Cells, J. Electrochem. Soc., 152 (2) A439-A444 (2005). 
[3] Z. Jiao, N. Shikazono, and N. Kasagi, Quantitative Characterization of SOFC nickel-YSZ Anode Microstructure Degradation Based on Focused-Ion-Beam 3D-Reconstruction Technique, J. Electrochem. Soc., 159 (3), pp. B285-B291 (2012).

[4] H. Iwai, N. Shikazono, T. Matsui, H. Teshima, M. Kishimoto, R. Kishida, D. Hayashi K. Matsuzaki, D. Kanno, M. Saito, H. Muroyama, K. Eguchi, N. Kasagi, H. Yoshida, Quantification of SOFC anode microstructure based on dural beam FIB-SEM technique, $J$. Power Sources, 195, 955-961 (2010).

[5] R. Barfod, M. Mogensen, T. Klemenso, A. Hagen, Y. Liu and P. Hendriksen, Detailed Characterization of Anode-Supported SOFCs by Impedance Spectroscopy, J.Electrochem. Soc., 154 (4), pp. B371-B378(2007) .

[6] H-Y. Chen, Simulation of Solid Oxide Fuel Cell Electrodes with complex Microstructure, Ph.D. thesis, The University of Michigan (2011).

[7] A. Tsoga and P. Nikologpoulos. Surface and grain-boundary energies in yttria-stabilized zirconia (YSZ-8 mol \%), J. Materials Science, 31, pp. 5409-5413, (1996).

[8] K. Shikata, S. Hara, N. Shikazono, S. Izumi and S. Sakai, Kinetic Monte Carlo Simulations of Microstructural Evolution in Solid Oxide Fuel Cell Cermet Anode, Proc. IUMRS-International Conference on Electronic Materials, A-2-P26-014 (2012). 
[9] Z. Jiao, G. H. Lee, N. Shikazono and N. Kasagi, Quantitative Study on the Correlation Between Solid Oxide Fuel Cell Ni-YSZ Composite Anode Performance and Sintering Temperature Based on Three-dimensional Reconstruction, J. Electrochem. Soc. 159 (7), pp. F278-F286 (2012).

[10] S. Osher and J. Sethian, Fronts Propagating with Curvature Dependent Speed: Algorithms Based on Hamilton Jacobi Formulations, J. Comp. Phys.., 79, pp. 1249 (1988).

[11] S. Osher, R. Fedkiw, Level Set Methods and Dynamic Implicit Surfaces, Springer, New York, (2003).

[12] J. S. Suri, S. Laxminarayan, PDE \& Level Sets Algorithmic Approaches to Static \& Motion Imagery, Kluwer Academic / Plenum Publishers (2002).

[13] RIKEN, Library for creating coded distance functions from shape data (http: //vcad-hpsv.riken.jp/)

[14] H. Y. Chen, H. C. Yu, J. S. Cronin, J. R. Wilson, S. A. Barnett, K. Thoroton, Simulation of coarsening in the three-phase solid oxide fuel cell anodes, J. Power Sources, 196, pp. 1333-1337(2011).

[15] X.Mantzouris, N. Zouvelou, D. Skarmoutsos, P. Nikolopoulos, and F. Tietz, Interfacial Properties and Structure Stability of Ni/Y-2 O-3-ZrO2-TiO2 Cermet Anodes for Solid Oxide Fuel Cells, J. Mat. Sci., 31, pp. 2471-2475 (2005). 
Tables

Table 1

\begin{tabular}{|c|c|c|c|c|}
\hline $\begin{array}{c}\text { Sintering } \\
\text { temperature }\end{array}$ & $\begin{array}{c}\text { After initial } \\
\text { reduction } \\
{\left[\mu \mathrm{m}^{3}\right]}\end{array}$ & $\begin{array}{c}\text { After } 100 \mathrm{~h} \\
\text { discharge } \\
{\left[\mu \mathrm{m}^{3}\right]}\end{array}$ & $\begin{array}{c}\text { After } 250 \mathrm{~h} \\
\text { discharge } \\
{\left[\mu \mathrm{m}^{3}\right]}\end{array}$ & $\begin{array}{c}\text { After 650h } \\
\text { discharge } \\
{\left[\mu \mathrm{m}^{3}\right]}\end{array}$ \\
\hline $1400^{\circ} \mathrm{C}$ & $12.7 \times 7.8 \times 9.8$ & $11.6 \times 8.1 \times 9.4$ & $11.4 \times 7.6 \times 9.9$ & - \\
\hline $1450^{\circ} \mathrm{C}$ & $18.3 \times 10.6 \times 8.4$ & $18.5 \times 12.1 \times 7.0$ & - & $14.0 \times 8.3 \times 11.1$ \\
\hline $1500^{\circ} \mathrm{C}$ & $11.9 \times 7.2 \times 11.1$ & $11.5 \times 6.5 \times 11.2$ & - & - \\
\hline
\end{tabular}

Table 2

\begin{tabular}{|c|c|c|c|c|c|c|}
\hline \multirow{2}{*}{ Sample } & \multicolumn{2}{|c|}{ Ni } & \multicolumn{2}{c|}{ YSZ } & \multicolumn{2}{c|}{ Pore } \\
\cline { 2 - 7 } & $\begin{array}{c}\text { Mean } \\
{[\mathrm{deg}]}\end{array}$ & $\begin{array}{c}\text { Standard } \\
\text { Deviation } \\
{[\mathrm{deg}]}\end{array}$ & $\begin{array}{c}\text { Mean } \\
{[\mathrm{deg}]}\end{array}$ & $\begin{array}{c}\text { Standard } \\
\text { Deviation } \\
{[\mathrm{deg}]}\end{array}$ & $\begin{array}{c}\text { Mean } \\
{[\mathrm{deg}]}\end{array}$ & $\begin{array}{c}\text { Standard } \\
\text { Deviation } \\
{[\mathrm{deg}]}\end{array}$ \\
\hline $\begin{array}{c}\text { After initial } \\
\text { reduction }\end{array}$ & 143.2 & 24.7 & 98.3 & 44.7 & 118.5 & 38.9 \\
\hline 100h discharge & 147.4 & 24.0 & 92.7 & 46.2 & 119.9 & 40.5 \\
\hline 250h discharge & 142.7 & 27.3 & 94.5 & 44.5 & 122.8 & 40.9 \\
\hline
\end{tabular}

Table 3

\begin{tabular}{|c|c|c|c|c|c|c|}
\hline \multirow{2}{*}{ Sample } & \multicolumn{2}{|c|}{ Ni } & \multicolumn{2}{c|}{ YSZ } & \multicolumn{2}{c|}{ Pore } \\
\cline { 2 - 7 } & $\begin{array}{c}\text { Mean } \\
{[\mathrm{deg}]}\end{array}$ & $\begin{array}{c}\text { Standard } \\
\text { Deviation } \\
{[\mathrm{deg}]}\end{array}$ & $\begin{array}{c}\text { Mean } \\
{[\mathrm{deg}]}\end{array}$ & $\begin{array}{c}\text { Standard } \\
\text { Deviation } \\
{[\mathrm{deg}]}\end{array}$ & $\begin{array}{c}\text { Mean } \\
{[\mathrm{deg}]}\end{array}$ & $\begin{array}{c}\text { Standard } \\
\text { Deviation } \\
{[\mathrm{deg}]}\end{array}$ \\
\hline $\begin{array}{c}\text { After initial } \\
\text { Reduction }\end{array}$ & 142.6 & 25.9 & 135.2 & 37.2 & 82.2 & 39.8 \\
\hline
\end{tabular}




\begin{tabular}{|c|c|c|c|c|c|c|}
\hline 100h discharge & 155.7 & 24.0 & 82.7 & 48.3 & 121.6 & 42.5 \\
\hline 650h discharge & 153.1 & 24.3 & 88.8 & 52.5 & 118.1 & 46.7 \\
\hline
\end{tabular}

Table 4

\begin{tabular}{|c|c|c|c|c|c|c|}
\hline \multirow{2}{*}{ Sample } & \multicolumn{2}{|c|}{ Ni } & \multicolumn{2}{c|}{ YSZ } & \multicolumn{2}{c|}{ Pore } \\
\cline { 2 - 7 } & $\begin{array}{c}\text { Mean } \\
{[\mathrm{deg}]}\end{array}$ & $\begin{array}{c}\text { Standard } \\
\text { Deviation } \\
{[\mathrm{deg}]}\end{array}$ & $\begin{array}{c}\text { Mean } \\
{[\mathrm{deg}]}\end{array}$ & $\begin{array}{c}\text { Standard } \\
\text { Deviation } \\
{[\mathrm{deg}]}\end{array}$ & $\begin{array}{c}\text { Mean } \\
{[\mathrm{deg}]}\end{array}$ & $\begin{array}{c}\text { Standard } \\
\text { Deviation } \\
{[\mathrm{deg}]}\end{array}$ \\
\hline $\begin{array}{c}\text { After initial } \\
\text { reduction }\end{array}$ & 134.7 & 28.5 & 138.3 & 32.3 & 87.0 & 36.6 \\
\hline 100h discharge & 144.9 & 25.1 & 112.8 & 44.6 & 102.3 & 41.3 \\
\hline
\end{tabular}

Table 5

\begin{tabular}{|c|c|c|c|}
\hline Samples & $\begin{array}{c}\text { YSZ/Pore } \\
{\left[\mathrm{Jm}^{-2}\right]}\end{array}$ & $\begin{array}{c}\text { Ni/Pore } \\
{\left[\mathrm{Jm}^{-2}\right]}\end{array}$ & $\begin{array}{c}\mathrm{Ni} / \mathrm{YSZ} \\
{\left[\mathrm{Jm}^{-2}\right]}\end{array}$ \\
\hline $\begin{array}{c}\text { After initial } \\
\text { reduction }\end{array}$ & 1.40 & 2.31 & 2.05 \\
\hline 100h discharge & 1.40 & 2.60 & 2.25 \\
\hline 250h discharge & 1.40 & 2.30 & 1.94 \\
\hline
\end{tabular}

Table 6

\begin{tabular}{|c|c|c|c|}
\hline Samples & $\begin{array}{c}\text { YSZ/Pore } \\
{\left[\mathrm{Jm}^{-2}\right]}\end{array}$ & $\begin{array}{c}\mathrm{Ni} / \text { Pore } \\
{\left[\mathrm{Jm}^{-2}\right]}\end{array}$ & $\begin{array}{c}\mathrm{Ni} / \mathrm{YSZ} \\
{\left[\mathrm{Jm}^{-2}\right]}\end{array}$ \\
\hline $\begin{array}{c}\text { After initial } \\
\text { reduction }\end{array}$ & 1.40 & 1.62 & 2.28 \\
\hline 100h discharge & 1.40 & 3.37 & 2.90 \\
\hline 650h discharge & 1.40 & 3.09 & 2.93 \\
\hline
\end{tabular}


Table 7

\begin{tabular}{|c|c|c|c|}
\hline Samples & $\begin{array}{c}\text { YSZ/Pore } \\
{\left[\mathrm{Jm}^{-2}\right]}\end{array}$ & $\begin{array}{c}\mathrm{Ni} / \text { Pore } \\
{\left[\mathrm{Jm}^{-2}\right]}\end{array}$ & $\begin{array}{c}\mathrm{Ni} / \mathrm{YSZ} \\
{\left[\mathrm{Jm}^{-2}\right]}\end{array}$ \\
\hline $\begin{array}{c}\text { After initial } \\
\text { reduction }\end{array}$ & 1.40 & 1.31 & 1.97 \\
\hline 100h discharge & 1.40 & 2.24 & 2.38 \\
\hline
\end{tabular}

\section{Figure and Table Captions}

Fig. 1 SEM images of anodes sintered at $1400^{\circ} \mathrm{C}$ (left), $1450^{\circ} \mathrm{C}$ (middle) and $1500^{\circ} \mathrm{C}$ (right).

Fig. 2 The process of obtaining level set function from FIB-SEM reconstructed data.

Fig. 3 Three dimensional reconstructed microstructures of the sample sintered at $1450^{\circ} \mathrm{C}$. After reduction (left), after 100h discharge (middle), after 250h discharge (right), Green: Ni, Blue: YSZ.

Fig. 4 Comparison between SEM and level set function images. (a) FIB-SEM, level set functions of (b) Ni,(c) YSZ and (d) Pore. Ni: white, YSZ: grey, Pore: black.

Fig. 5 Normal vectors of the interfaces at the vicinity of triple phase boundary.

Fig. 6 Triple phase boundary direction vector.

Fig. 7 Normal vector projected into the plane orthogonal to the TPB direction

Fig. 8 Surface tensions and contact angles at triple phase boundary

Fig. 9 Probability distribution function of local contact angles for the sample sintered at $1400{ }^{\circ} \mathrm{C}$

Fig. 10 Probability distribution function of local contact angles for the sample sintered at $1450{ }^{\circ} \mathrm{C}$. 
Fig. 11 Probability distribution function of local contact angles for the sample sintered at $1500{ }^{\circ} \mathrm{C}$.

Table 1 The sizes of anode samples sintered at three different temperatures, $1400{ }^{\circ} \mathrm{C}, 1450{ }^{\circ} \mathrm{C}$, and $1500^{\circ} \mathrm{C}$.

Table 2 Average contact angles and standard deviations of Ni, YSZ and pore at triple phase boundary for the samples sintered at $1400{ }^{\circ} \mathrm{C}$.

Table 3 Average contact angles and standard deviations of Ni, YSZ and pore at triple phase boundary for the samples sintered at $1450{ }^{\circ} \mathrm{C}$.

Table 4 Average contact angles and standard deviations of Ni, YSZ and pore at triple phase boundary for the samples sintered at $1500{ }^{\circ} \mathrm{C}$.

Table 5 Surface tensions at triple phase boundary for the sample sintered at $1400{ }^{\circ} \mathrm{C}$.

Table 6Surface tensions at triple phase boundary for the sample sintered at $1450{ }^{\circ} \mathrm{C}$.

Table 7 Surface tensions at triple phase boundary for the sample sintered at $1500{ }^{\circ} \mathrm{C}$. 


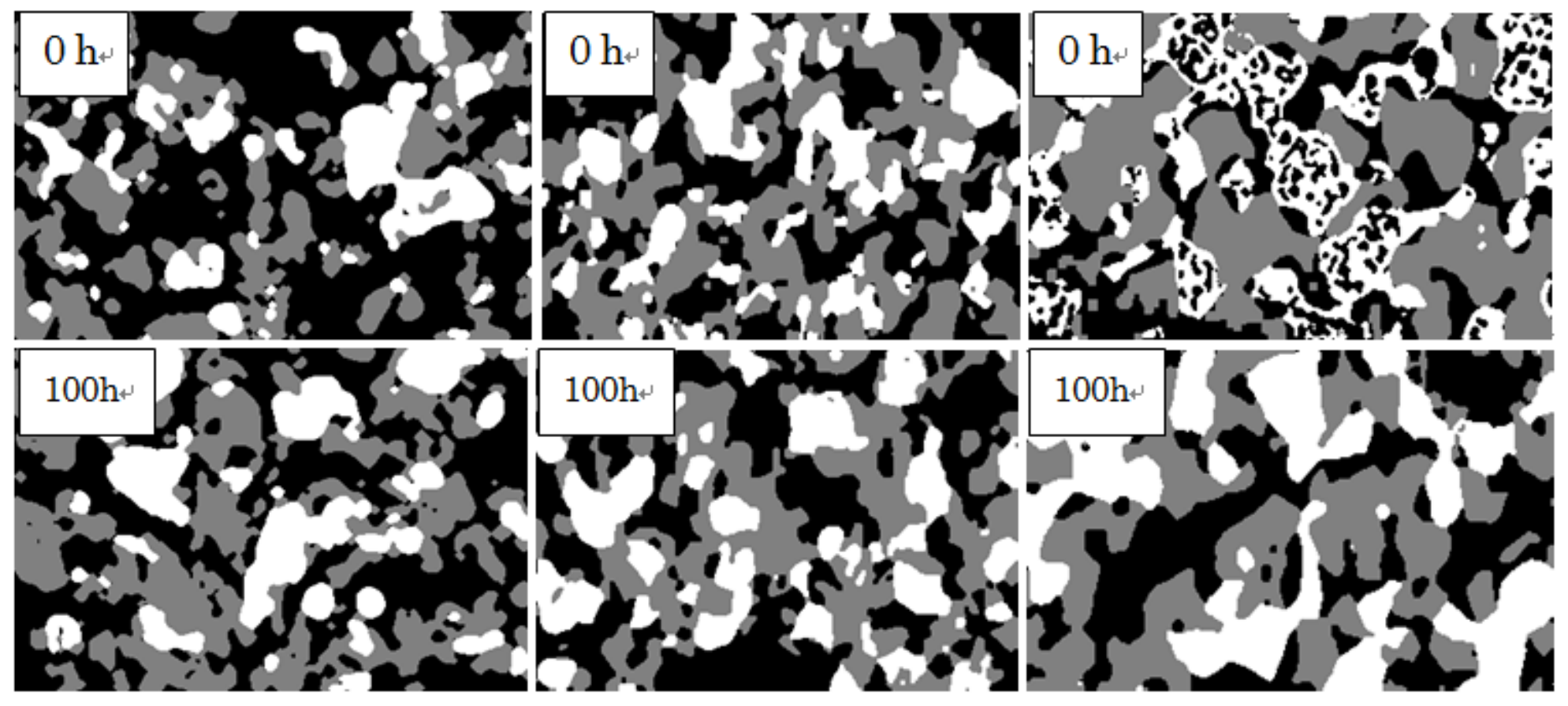


Figure 2
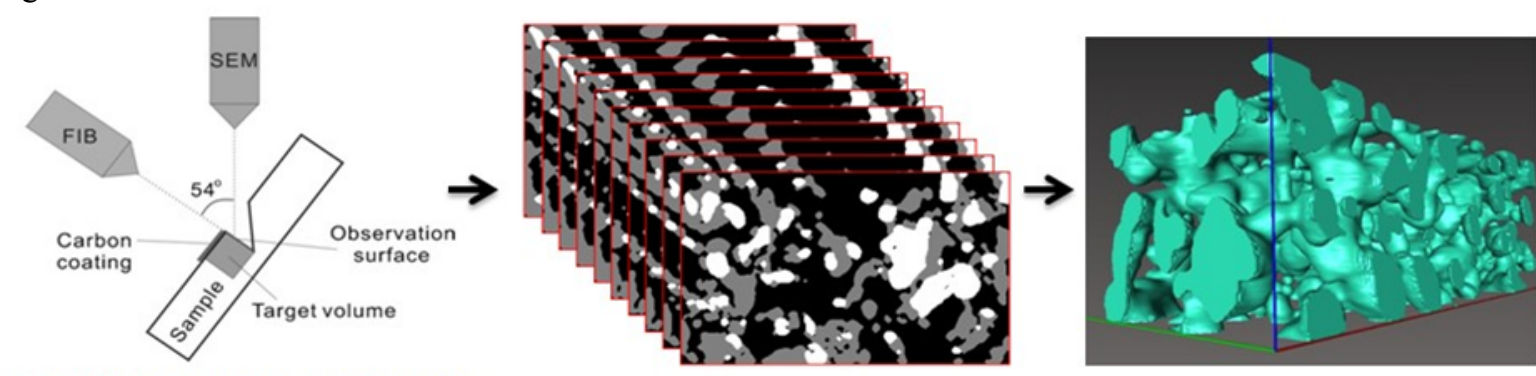

A series of 2D images of an anode

$3 \mathrm{D}$ reconstruction of Nickel in anode

Schematic diagram of FIB-SEM setting 

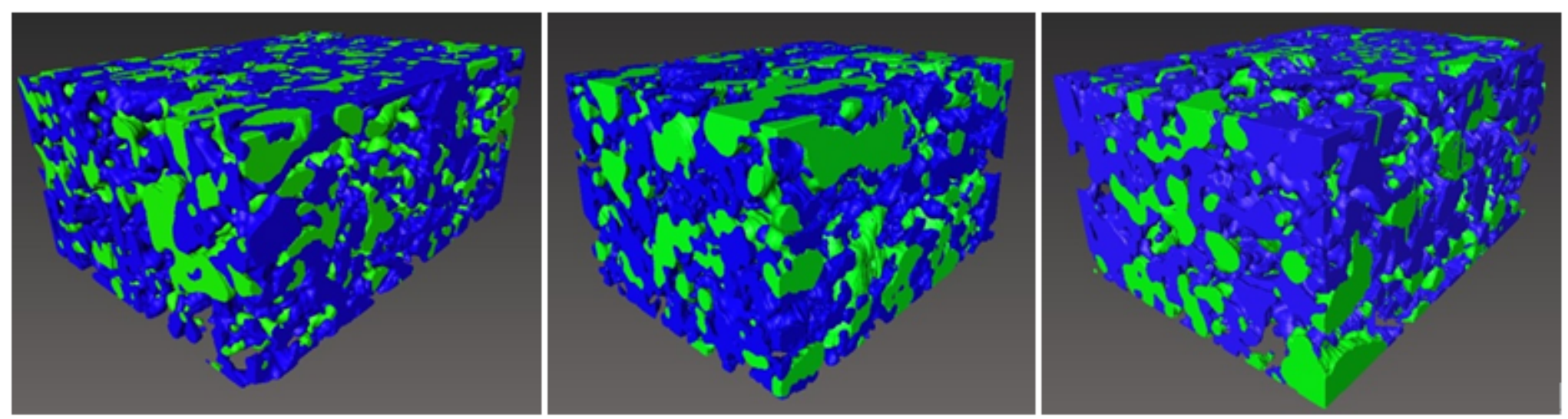


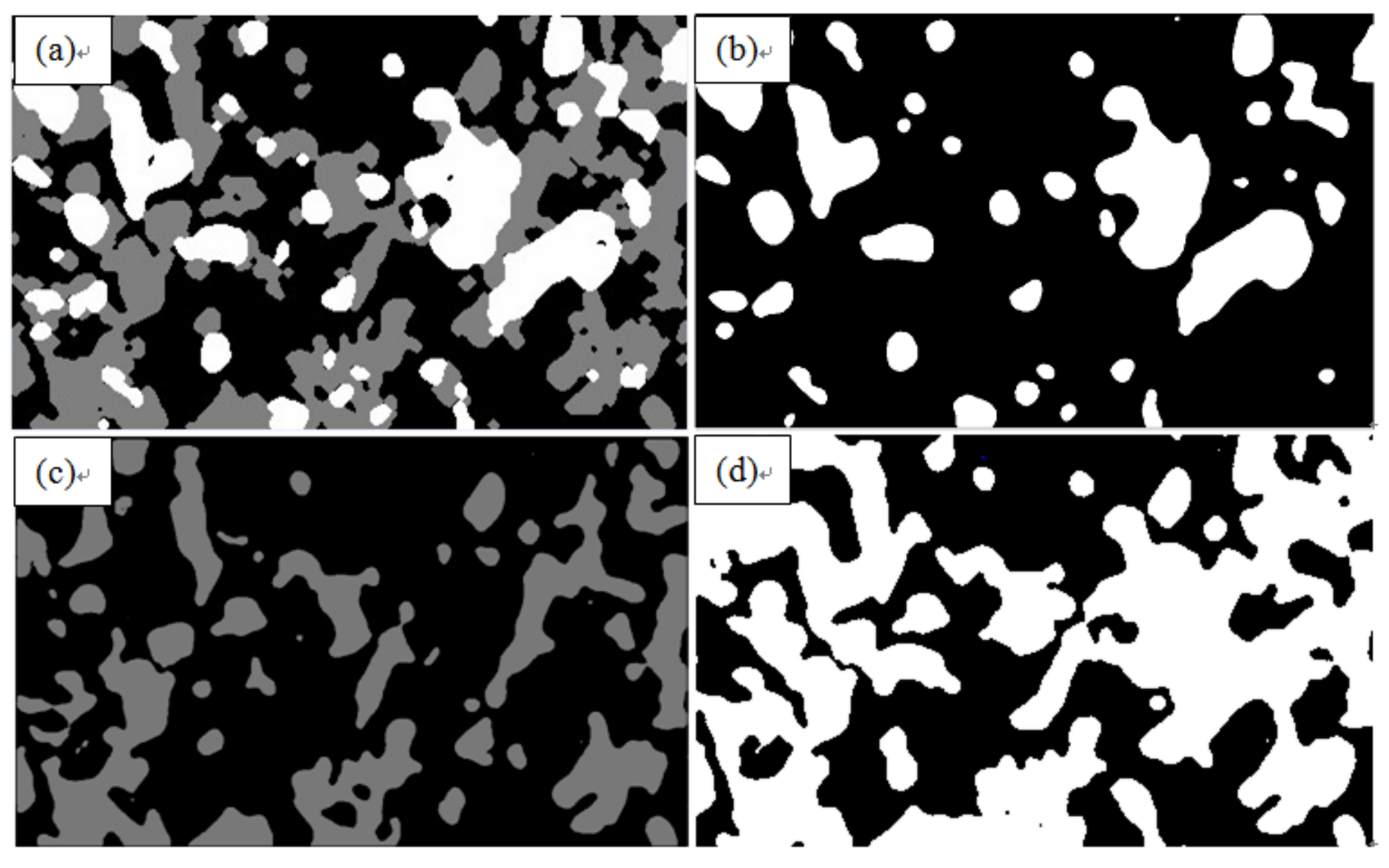




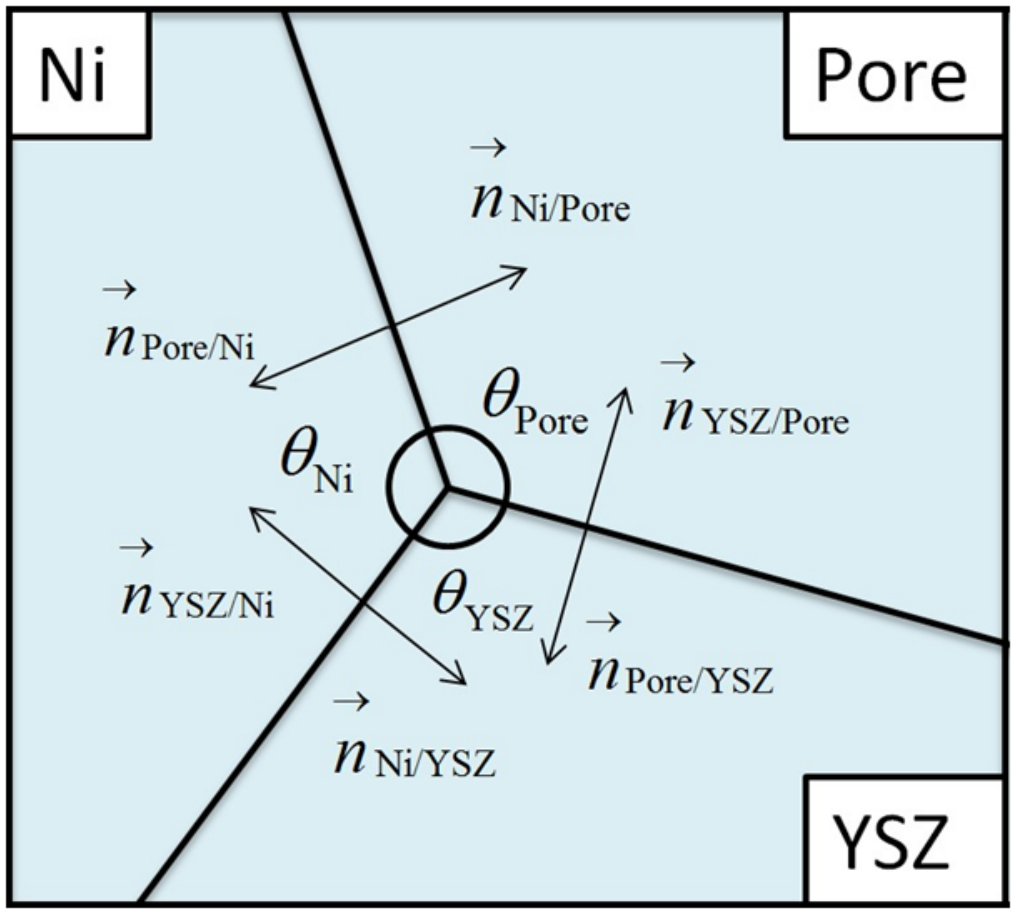




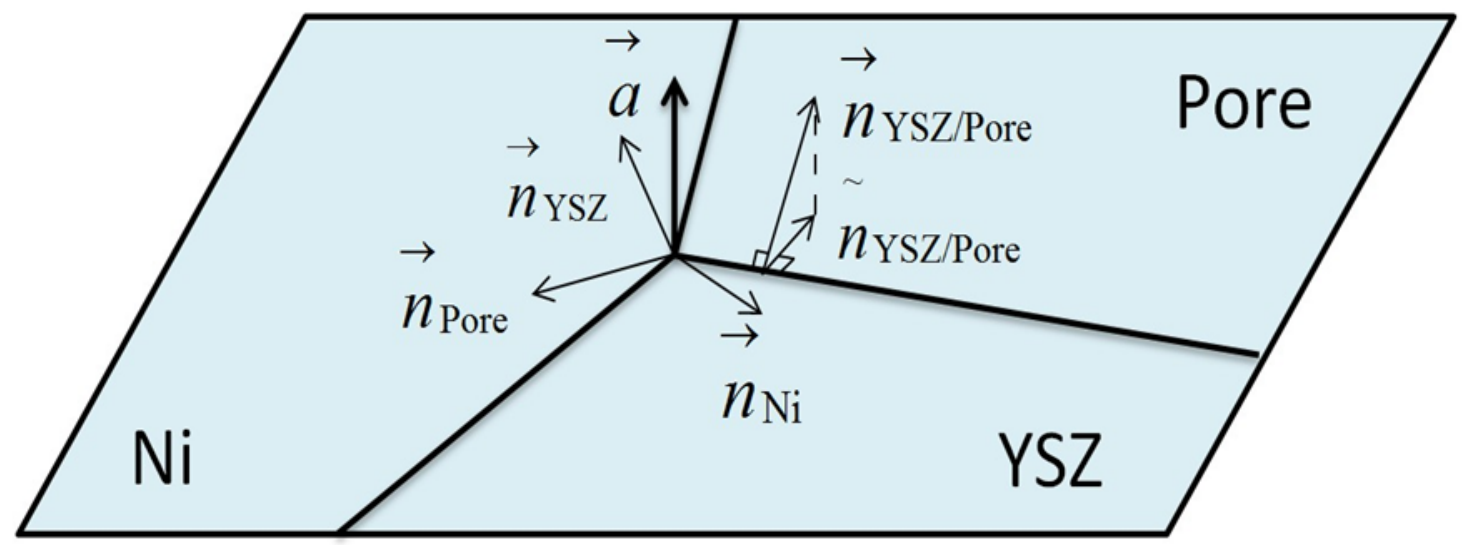


Figure 7

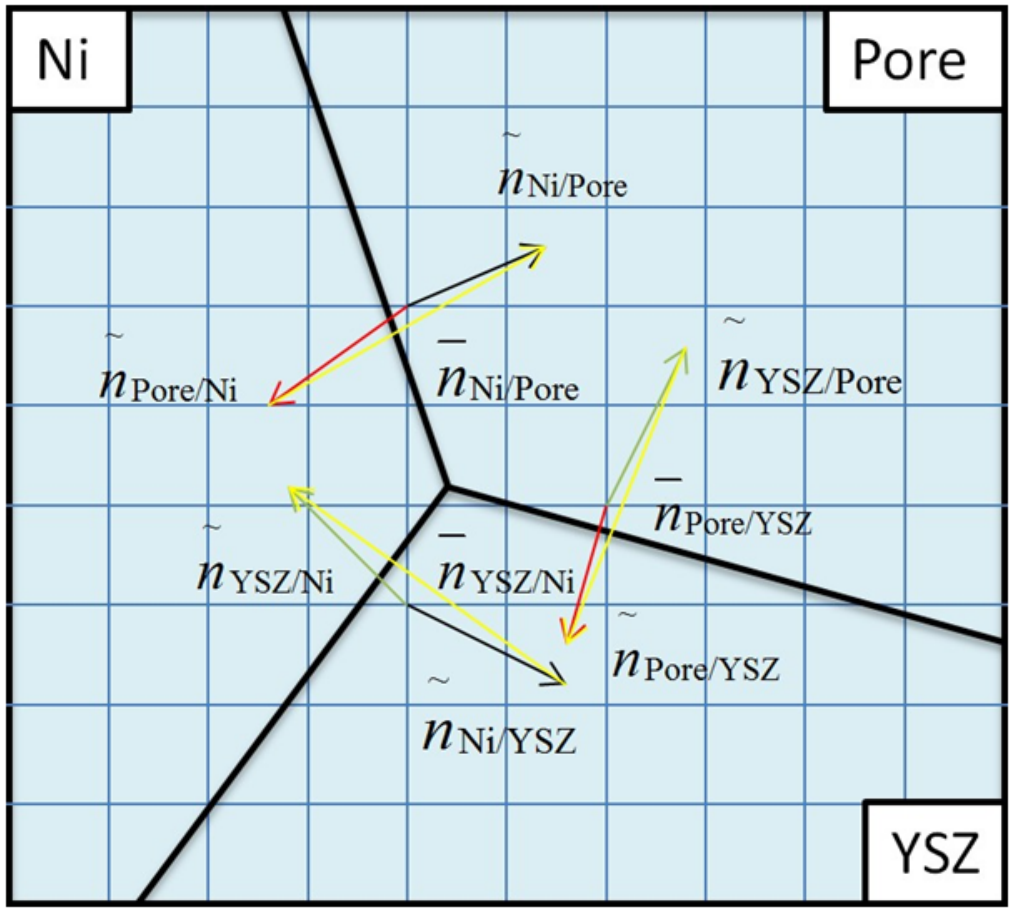


Figure 8

Ni

$\gamma_{\mathrm{Ni} / \mathrm{YSZ}}$

YSZ

\section{Pore}

$\gamma_{\mathrm{Ni} / \text { Pore }}$

$\theta_{\text {Pore }}$

$\theta_{\mathrm{YSZ}} \gamma_{\mathrm{YSZ} / \mathrm{Pore}}$ 
Figure 9
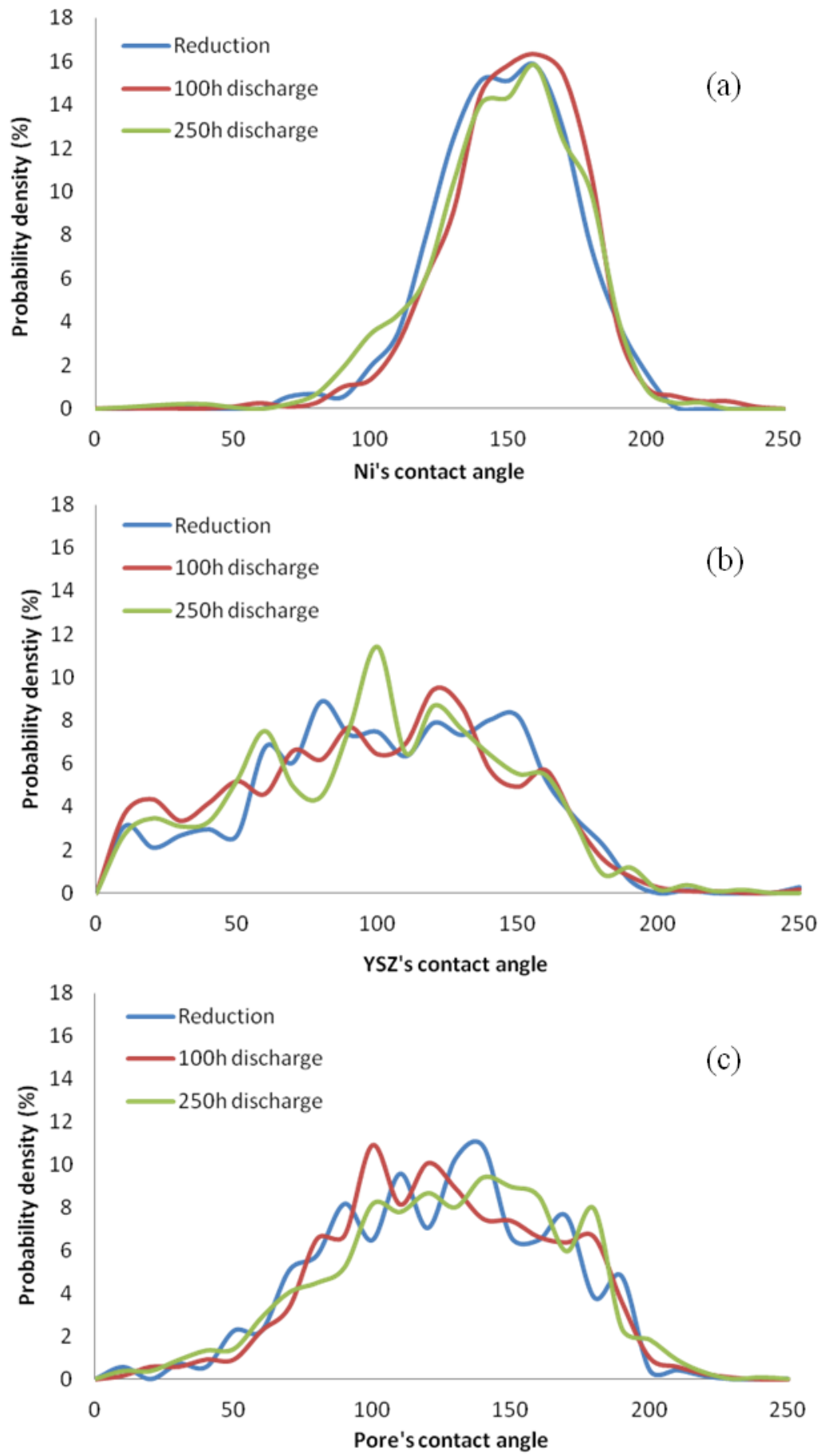
Figure 10
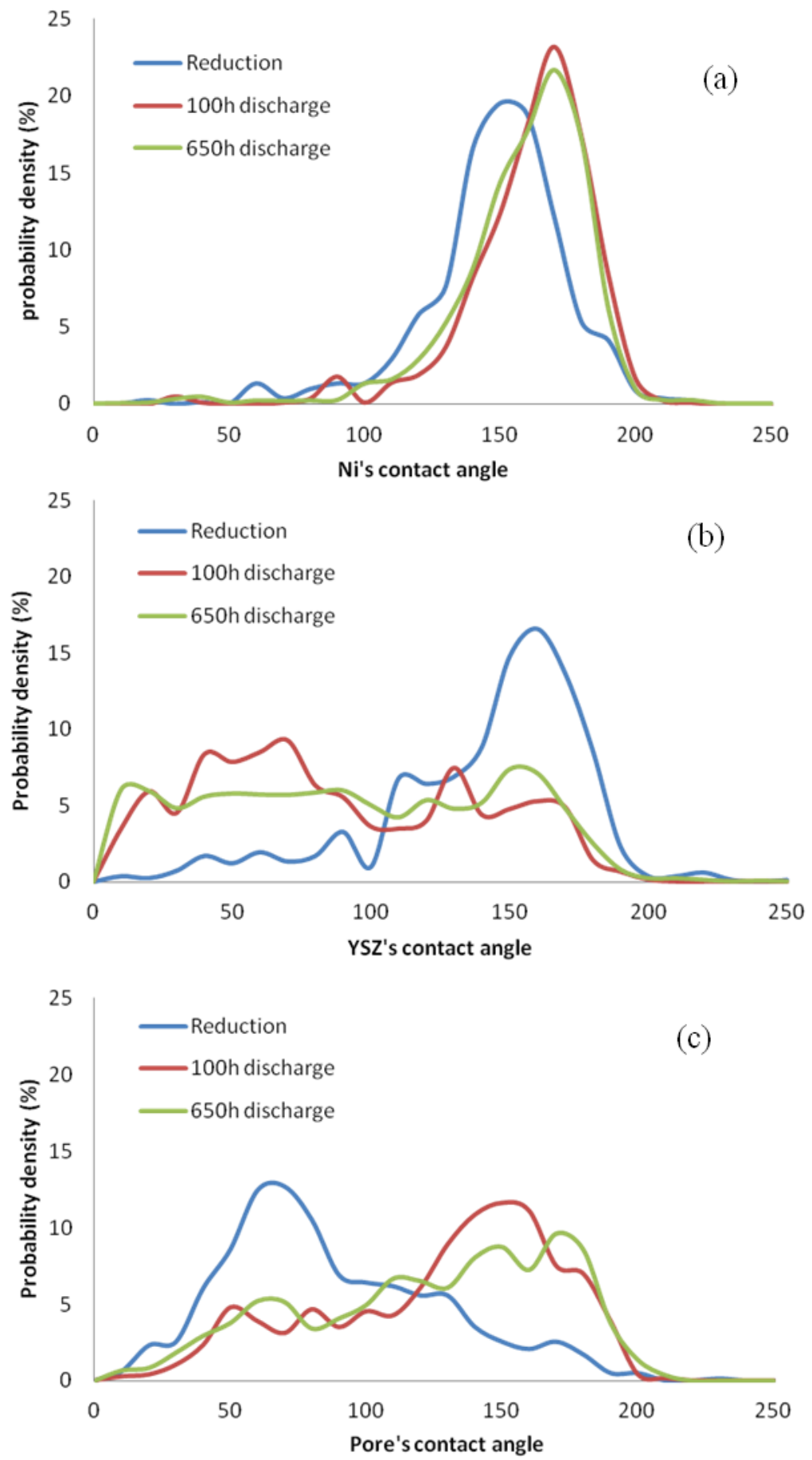

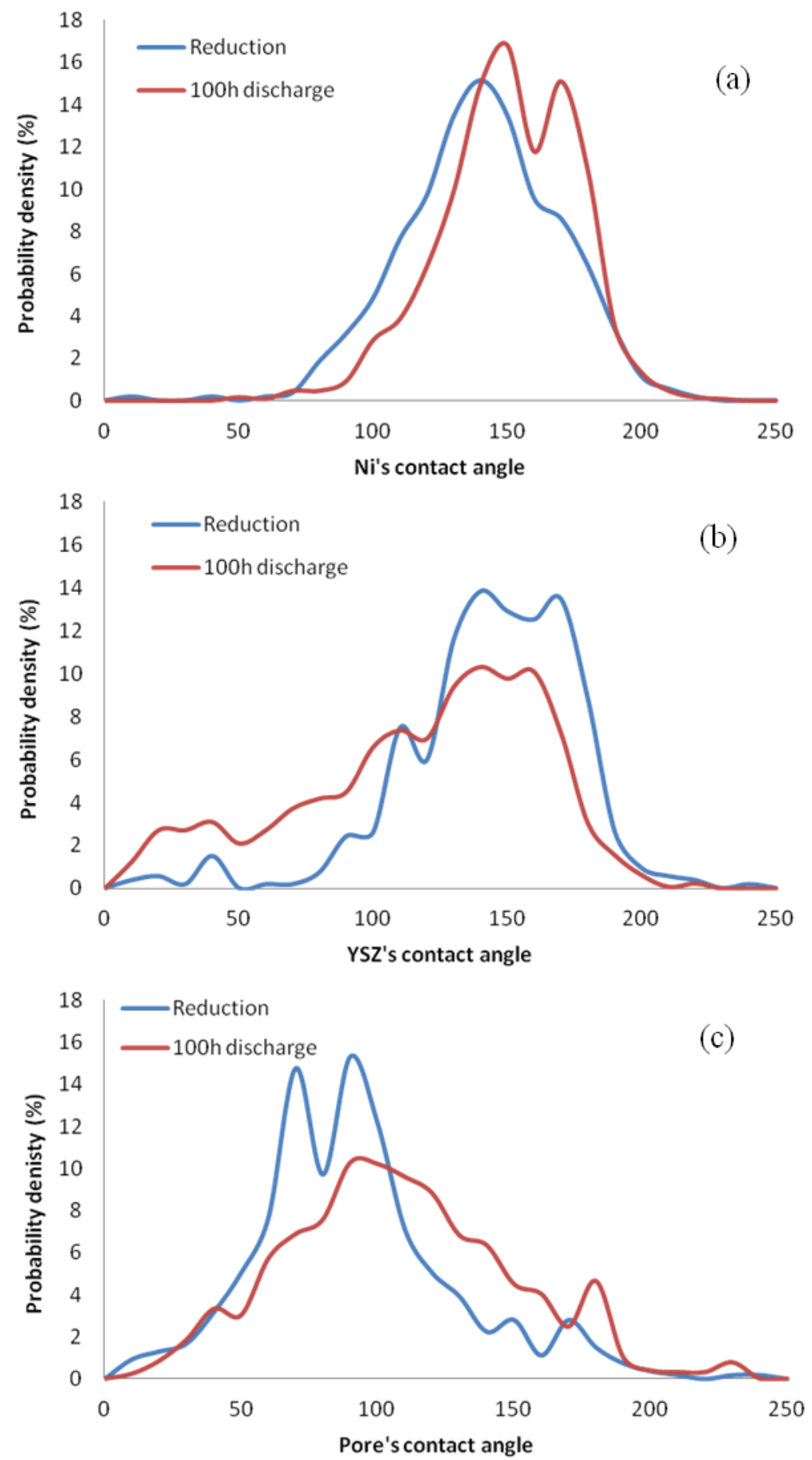